\title{
Triple Negative Breast Cancer: A Review of Clinicopathologic Characteristics And Treatment Options
}

\author{
Laura J. Porro ${ }^{1}$, Amy A. Mrazek ${ }^{1}$, Techksell M. Washington ${ }^{2}$ and Celia Chao ${ }^{*}, 1$ \\ ${ }^{I}$ Departments of Surgery and Medicine, ${ }^{2}$ Division of Hematology-Oncology, University of Texas Medical Branch, \\ Galveston, TX, USA
}

\begin{abstract}
Breast cancer is the second leading cause of cancer death in women. Approximately $15-20 \%$ are triple negative breast cancer (TNBC: no protein expression of estrogen receptor, progesterone receptor, nor human epidermal growth factor receptor 2), representing one of the most challenging molecular subtypes of breast cancer. TNBC encompasses a heterogenous group of breast cancers that are not generally responsive to targeted therapies for hormone and growth factor receptors. Compared to their hormone receptor-positive counterparts, TNBC cases are associated with poor prognosis, worse overall survival and earlier recurrence. The purpose of this review is to describe the clinicopathologic features, molecular variants, associations with the BRCA genes, and therapeutic approaches for TNBC. New TNBC-targeted drug therapies are currently under investigation and include poly-ADP-ribose polymerase (PARP) inhibitors, platinum-based drugs, anti-epidermal growth factor receptor (EGFR) inhibitors, and anti-vascular endothelial growth factor receptor (VEGF) inhibitors. Both clinical trials and basic research are needed to further our understanding of the best treatment options for patients with TNBC.
\end{abstract}

Keyword: Triple negative breast cancer.

\section{INTRODUCTION}

Breast cancer is the second leading cause of cancer death in women. Reports from the American Cancer Society estimates that the incidence of breast cancer in 2013 for the United States is 122 per 100,000 women, with a mortality rate of 23 per 100,000 [1]. New pharmacotherapeutics, increased awareness, and early detection have resulted in decreased mortality, with a 5-year overall survival of $90 \%$ today, compared to $75 \%$ survival in the mid-1970s [1]. Breast cancer is a complex and heterogeneous condition; the molecular characteristics that define a breast cancer impact treatment selection and prognosis. Tailoring therapy based on molecular subtypes of breast cancer has markedly improved clinical outcomes [2, 3]. However, the "triple negative" phenotype has been difficult to target and is associated with poor survival.

"Triple Negative Breast Cancers" (TNBC) are comprised of heterogeneous breast cancers, defined broadly as breast cancers that lack protein expression of estrogen receptor (ER), progesterone receptor (PR) and human epidermal factor receptor 2 (HER2) by immunohistochemistry (IHC). TNBC accounts for approximately $15-20 \%$ of newly diagnosed breast tumors [4, 5]. Due to differences in pathologic interpretation, the definition of TNBC may vary. One problem that contributes to the confusion is the discrepancies in the IHC cutoffs $(<1 \%$ or $<10 \%)$ applied to determine ER and PR status [6-8]. Additionally, discordance

\footnotetext{
*Address correspondence to this author at the Department of Surgery, University of Texas Medical Branch, 301 University Boulevard, Galveston, Texas 77555, USA; Tel: 409-772-0698; Fax: 409-772-0088;

E-mail: cechao@utmb.edu
}

between determinations of HER2 positivity achieved by IHC or by fluorescence in situ hybridization (FISH) has been documented $[8,9]$. Accurate determination of the HER2 status is crucial since this marker is used not only for treatment selection but also as a prognostic tool. To address these issues, the American Society of Clinical Oncology (ASCO) and the College of American Pathologist (CAP) have issued guidelines to standardize the parameters used to determine ER, PR, and HER2 positivity. For ER and PR positivity, current guidelines recommend a threshold $\geq 1 \%$ of immunoreactive cells [6]. Recommendations for HER2 positivity by IHC is $>10 \%(3+)$ evidence of protein expression in tumor cells, or by FISH, where overexpression of HER2 is determined by the ratio of the copy number over the number of evaluated nuclei in at least 20 cells. Specific recommendations on tissue fixation and selection of antibodies are important since these factors have led to variability in results [10]. Overlap with BRCA1 germline mutation carrier is another confusing subject. Most BRCA1 mutation carriers are triple negative and have a basal-like phenotype; however, their clinical management may differ from the non-BRCA1 mutant TNBC patient. The purpose of this review is to describe the clinicopathologic features and therapeutic approaches associated with TNBC.

\section{BREAST CANCER MOLECULAR SUBTYPES}

Patient prognosis are determined by clinical-pathologic factors such as age, race, menopausal status, family history, stage at diagnosis, tumor histology, and immunohistochemical stains for ER/PR status and HER2 expression. About $75-80 \%$ of the breast cancers are hormone receptor positive. In general, when compared to hormone receptor positive tumors, TNBC have a higher proliferation rate $(54 \%$ 
vs 17\%) [11, 12]. Over the past decade, gene expression profiling and their correlation to immunohistochemical markers have led to the identification of different molecular subtypes of breast cancer: luminal A, luminal B, HER2 positive, and basal-like [4, 13, 14].

With regard to overall survival, significant differences exist between the four molecular subgroups. Luminal A breast cancers originate from cells lining the mammary ducts, are ER/PR positive and HER2 negative, and have the longest relapse-free and overall survival (OS) [15]. Also derived from the luminal cells of mammary ducts, Luminal B tumors may have lower ER/PR expression, but are HER2 positive. HER2 positive tumors are ER/PR negative with overexpression of the HER2 gene, and are usually associated with poor prognosis [5]. Basal-like breast cancers are derived from the basal layer of the breast; they have a high nuclear proliferation rate $[5,16]$. Basallike tumors are ER/PR negative, but express basal cytokeratin $5 / 6$ and 17 . The majority of basal-like tumors harbor a tumor suppressor TP53 mutation [5]. Basal-like and HER2-positive subtypes have the shortest relapse-free and OS [13]. In a study by Montagna et al. [15] using a large cohort of patients $(\mathrm{n}=8801)$, including $781 \mathrm{TNBC}$, the 5-year disease free survival (DFS) for TNBC is $77 \%$, compared to $68 \%$ for the HER2+, $95 \%$ for the Luminal A and $84 \%$ for the Luminal B subtypes. The 5-year OS was $83 \%$ for TNBC, and 94\% for HER2positive, $98 \%$ for the luminal A and $94 \%$ for the luminal B.

\section{Basal-Like Molecular Subtype}

The basal-like molecular subtype is a subset of TNBC. While TNBC is simply defined by IHC/FISH staining criteria, no clear consensus exists to define basal-like breast cancer [8, $16]$. About $77 \%$ of the basal-like tumors are TNBC; and among the TNBC, $70-80 \%$ are basal-like $[8,17,18]$. Commonly, basallike tumors are characterized by the presence of basal markers such as epidermal growth factor receptor (EGFR), cytokeratins (CK) 5, CK6, CK14, CK17, p-cadherin, p63, c-kit, and smooth muscle actin [19-23]. Lehmann et al. [24] have used gene expression profiling to characterize TNBC using data from 587 TNBC. They define 6 subtypes of TNBC: basal-like 1 (increased cell cycle genes, DNA damage response genes, and overexpression of $\mathrm{Ki}-67 \mathrm{mRNA}$, suggesting increased sensitivity to taxanes); basal-like 2 (high expression of TP63); immunomodulatory (presence of profuse immune infiltrate, immune cell-surface antigen expression, and cytokine signaling); mesenchymal (overexpress genes involved in cell motility); mesenchymal stem-like (upregulation of genes associated with motility, angiogenesis, and stem-cell associated genes); and luminal androgen receptor subtype (increased gene expression of androgen receptors) [24]. Other investigators have proposed different subclassifications, such as luminal C, claudin-low, and C-kit [23-26]. The claudin-low subtype has a mesenchymal phenotype and is characterized by decreased cellto-cell junction proteins like claudin and E-cadherin, as well as the presence of prominent immune infiltrates [23]. However, these molecular descriptions and their response to targeted therapies require further study and validation.

\section{BRCA1/2 Mutations}

Germ-line mutations in the BRCA1 and BRCA2 gene confer an increased lifetime risk of breast cancer since these genes are involved in DNA repair and maintenance of genomic integrity [27]. The Consortium of Investigators of
Modifiers of BRCA1/2 analyzed 3,797 BRCA1 and 2,392 BRCA2 mutation carriers, reporting that $69 \%$ of BRCA1 mutation carriers had invasive TNBC, compared to only $16 \%$ of patients with BRCA2 mutations [28]. Also, TNBC and BRCA1 mutation were independently associated with younger age at diagnosis, as well as higher grade and stage tumors when compared with non-TNBC [28, 29]. BRCA1 carriers commonly express basal markers and are of the basal-like subtype [28]. The BRCA1 mutant subtype is present frequently in women of Ashkenazi Jewish heritage and is associated with a family history of breast and/or ovarian cancer. In contrast, African-American women more commonly have sporadic, non-BRCA-associated TNBC [29].

Identification of the BRCA1 mutation among patients with breast cancer has been used as a prognostic factor and as a tool for treatment selection [27]. Patients with BRCA1 mutations have been shown to have good response to DNA damaging agents such as platinum salts and poly-ADPribose polymerase (PARP) inhibitors $[30,31]$. Rather than a mutation inactivating the gene, "BRCAness" can be achieved via epigenetic promoter methylation, leading to dysfunctional BRCA1 gene expression [29, 32-34]. These TNBC tumors may also respond well to platinum agents and PARP inhibitors [34].

\section{Histologic Subtypes of TNBC}

The histologic subtype for the majority of TNBC is invasive ductal carcinoma (IDC) $(89 \%)$; other histologic subtypes include apocrine (4\%), lobular (2\%), adenoid cystic, metaplastic, papillary and medullary, which account for $1 \%$ of the cases. Each histologic subtype has different estimated 5 year OS: $84 \%$ for IDC, $82 \%$ for invasive lobular carcinomas, $88 \%$ for metaplastic and papillary, $92 \%$ for apocrine, and $100 \%$ for the medullary and adenoid cystic subtypes [15]. The lowest 5-year DFS is seen in the metaplastic subtype (55\%), compared to apocrine $(84 \%)$, IDC (77\%), papillary $(67 \%)$, lobular $(64 \%)$, and the adenoid and medullary subtypes (100\%) [15].

\section{CLINICAL PRESENTATION AND CHARACTERISTICS}

TNBC have been consistently shown to be more common in African-American women [6, 35, 36]. However, some studies have also found Hispanic women to have a higher incidence of TNBC $[26,37]$. TNBC is usually diagnosed at a younger age $[5,26,38]$, and presents at a higher stage and larger size when compared to the other breast cancer molecular subtypes. Most studies show that TNBC patients have poor prognosis, worse overall survival and earlier recurrence compared with their hormone receptor positive counterparts, even when the diagnosis was made at an early stage [39, 40]. Additionally, TNBC has more than $20 \%$ greater incidence of visceral metastasis compared to the other breast cancer subtypes, which commonly metastasize to bone $[37,41]$. This incidence of visceral relapse decreases dramatically with long-term follow-up and are comparable to that of non-TNBC [12]. Other factors, such as menopausal status, obesity, use of oral contraceptives and their influence in the incidence of triple negativity varies among studies [42]. Since TNBC predominantly affects younger patients, it can be expected that more patients within this group are premenopausal. Further evaluation to validate the 
relationship between obesity and TNBC must be done since the incidence of obesity among African-American/Hispanics women may be confounders.

\section{TREATMENT}

The lack of molecular targets identified in TNBC excludes this patient population from the benefits of endocrine or HER2-targeted therapies; therefore, standard chemotherapy in conjunction with surgery and/or radiation therapy remains the standard of care. Some radiation therapists advocate the use of post-mastectomy radiation in all patients with TNBC. The combination of radiotherapy with adjuvant chemotherapy following mastectomy, for the treatment of TNBC, showed a striking increase in the 5-year OS (90.4\%) compared to patients who received chemotherapy alone (78.7\%) [41]. The 5-year recurrence-free survival (RFS) was $88 \%$ in the radiotherapy group compared to $74.6 \%$ in the chemotherapy only group [41]. The addition of radiotherapy increased the time to distant metastasis by two or more years in patients with TNBC [41].

\section{CHEMOTHERAPY}

Most of the data to manage TNBC patients are derived from retrospective subset analyses of clinical trials which include all subtypes of breast cancers, rather than prospective randomized trials for TNBC patients only. Due to the aggressive nature of TNBC, with high and early incidence of recurrence, many experts advocate the administration of chemotherapy even in the event of node negative small tumors [40]. Patients with TNBC consistently demonstrate poor prognosis when compared with other molecular subtypes of breast cancer, regardless of treatment, and despite early stage disease $[39,43]$. The recurrence rate for stage I and small TNBC tumors have been reported between $12-23 \%$ and up to $46 \%$ in patients $<35$ years of age, compared to recurrence rates of $5 \%$ in patients with small HER2-positive cancers and $11 \%$ in small hormone positive breast cancers $[39,44]$.

TNBC is currently treated with anthracycline (doxorubicin, epirubicin) and taxane (paclitaxel, docetaxel) containing regimens. Docetaxel along with anthracycline containing regimens in TNBC have shown improved DFS $[43,45,46]$. Administration of 5-fluorouracil, epirubicin and cyclophosphamide followed by paclitaxel (FEC vs FEC-P) reduced the chances of relapse in TNBC by $47 \%$ and $67 \%$ in the basal-like phenotype with a seven-year DFS of $18 \%$ and $26 \%$, respectively [47]. Capecitabine is an oral pro-drug that converts to 5-fluorouracil in the tumor. The Finland Capecitabine Trial studied the effect of docetaxel and capecitabine followed by cyclophosphamide, epirubicin, capecitabine (TX/CEX), compared to no capecitabine (T/CEF). Patients with TNBC $(\mathrm{n}=202)$ showed the greatest benefit in recurrence-free survival with TX/CEX [48]. Additionally, the classical chemotherapeutic approach, consisting of cyclophosphamide, methotrexate and 5fluorouracil (CMF), has been shown to be beneficial for patients with TNBC $[49,50]$.

\section{Neoadjuvant Chemotherapy}

Neoadjuvant chemotherapy is an important treatment option for patients with advanced breast cancer for two reasons: 1) reduction of tumor burden to increase possibility of breast conserving surgery, and 2) the ability to assess the tumor's response to the drug. While some studies claim improvement in long-term survival for those patients who achieved the pathologic complete response (pCR) rate following neoadjuvant chemotherapy $[51,52]$, others show that pCR achievement does not improve the OS for the TNBC subgroup [37, 53]. Liedtke et al. [37] reported the clinical outcomes of TNBC patients $(n=255)$ who received neoadjuvant chemotherapy; the pCR was $22 \%$ compared to $11 \%$ in non-TNBC. However, the 3 -year progression-free survival (PFS) was lower in TNBC (63\%) than in nonTNBC (76\%), and the overall survival was $74 \%$ in TNBC vs $89 \%$ in the non-TNBC. They concluded that although TNBC have a higher $\mathrm{pCR}$ rate, patients with residual disease after neoadjuvant chemotherapy have the worse survival compared with non-TNBC patients.

In the neoadjuvant setting, capecitabine with docetaxel resulted in a pCR rate of $19 \%$ in TNBC patients, compared to $3 \%$ in the non-TNBC group; however, DFS was lower in TNBC patients [54].

\section{Metastatic Disease}

Capecitabine is also a treatment option after progression of the disease in patients previously treated with anthracycline/taxane. Other non-cross-resistant agents such as gemcitabine and vinorelbine are used as single agents after failure of anthracycline/taxane in TNBC, with pCR rates ranging from 28 to $40 \%$ compared to $3-14 \%$ without gemcitabine or vinorelbine [55-57]. Epothilone B ixabepilone and Eribulin recently gained FDA approval for the treatment of advanced disease and have been shown to be efficacious in TNBC patients $[58,59]$.

Another strategy in the treatment of metastatic breast cancer is the metronomic administration of cytotoxic agents, whereby lower doses are administered over a longer period of time. The purpose of these regimens is to achieve longer survival with fewer side effects. For HER2 negative breast cancers, Yoshimoto et al. [60] found that TNBC patients had an overall response rate of $44.4 \%$ with a progression-free survival of 10.7 months; and for ER/PR-positive patients, the response rates were $46.4 \%$ and 12.2 months PFS. It has been postulated that this treatment modality induces endothelial cells apoptosis, resulting in angiogenesis impairment [60]. This is an interesting approach that merits further investigation considering the lack of durability in the patient response to chemotherapy seen in TNBC.

Examples of other strategies are sequential monotherapy versus the use of combination chemotherapy, high dose vs dose dense regimens, anthracycline rechallenge as well as diverse treatment scheduling [61-63]. Despite having shown positive effects on TNBC in some cases, further studies are required to validate the findings.

\section{NEW TARGETED THERAPIES FOR TNBC}

\section{DNA Repair Damaging Agents}

New strategies in the treatment of TNBC BRCA1 mutation carriers involve the use of PARP inhibitors. Drugs such as olaparib, veliparib, and niraparib inhibit the PARP-1 enzyme, which is needed for base excision repair in the DNA repair process. PARP inhibition, combined with loss of 
DNA repair due to BRCA mutation, results in selective cell death for tumors with the BRCA1 germline mutation [64]. These drugs have been shown to be effective in patients with BRCA 1 or BRCA 2 mutation, including those with TNBC; however, these studies are in early phases and continued investigations are underway [65-67].

Iniparib, a drug with an unknown mechanism of action, was originally thought to be a PARP inhibitor. Phase II and phase III clinical trials have studied the effects of iniparib in combination with gemcitabine and carboplatin in patients with TNBC. Although the phase-II study $(\mathrm{N}=123 \mathrm{TNBC}$ patients) reported striking benefits with the addition of iniparib (overall response rate of 52\% compared to $32 \%$ for chemotherapy alone, $\mathrm{p}=0.02)$ [67], the phase-III study $(\mathrm{N}=$ 519 TNBC patients) failed to show significant results in PFS and OS when compared to patients on gemcitabine and carboplatin alone [68].

Platinum-based therapy, such as carboplatin and cisplatin, bind and crosslink DNA, which selectively will target BRCA-mutated cancer cells unable to repair from DNA damage. Platinum salts for use in metastatic TNBC have been investigated in various clinical trials based on the prevalence of BRCA1 mutation among TNBC. In vitro studies have documented a potential marker capable of predicting platinum sensitivity in TNBC: 60 to $80 \%$ of the TNBC harbor p53 mutations; co-expression of transactivated p73 and N-terminal truncated p63 (both part of the p53 tumor suppressor family) form a protein complex unit in TNBC tumors carrying the p53 mutation. Treatment with cisplatin reactivates the pro-apoptotic activity of p73 [69]. Platinum therapies have been investigated in combination with: cetuximab [70], taxane [71], gemcitabine [72], and paclitaxel [73] with variable results. For patients with metastatic TNBC or locally advanced TNBC, treatment with a cisplatin regimen improved DFS and OS [72, 74, 75]. However, other studies of platinum-based therapies have shown limited benefit in TNBC [76, 77], and thus, no conclusive results on the benefits of platinum can be made.

\section{Anti-Epidermal Growth Factor Receptor (EGFR)}

Over $40 \%$ of the TNBC basal-like subtype overexpress EGFR, and its presence has been commonly associated with worse prognosis [16, 43, 78, 79]. Compared to hormone receptor positive tumors, patients with TNBC are 6.5 times more likely to express EGFR ( $7 \%$ vs $49 \%$, respectively) [11]. However, a recent analysis of $253 \mathrm{TNBC}$ found no correlation between EGFR expression and unfavorable longterm outcomes [11]. In a retrospective study, TNBC overexpressing EGFR had better pCR rates when compared to non-TNBC in the neoadjuvant setting; however, on multivariate analysis, EGFR expression was not an independent predictor of OS $(\mathrm{p}=0.7)$ [80]. Additional studies investigating the use of EGFR inhibitors in TNBC are ongoing [78, 81, 82].

Data from clinical trials show that use of cetuximab, an anti-EGFR monoclonal antibody, only shows a moderate response rate in metastatic TNBC. Cetuximab has been investigated in combination with cisplatin, carboplatin, and carboplatin plus irinotecan, resulting in objective response rates (ORR), ranging between $18-49 \%$ with very limited effect on OS [70,83,84].
Lapatinib, an EGFR tyrosine kinase inhibitor that inhibits EGFR and HER2, was evaluated in several phase I and II studies. Although inhibition of HER2 was verified in tissue biopsies, there was no clinical benefit in TNBC [85, 87]. This drug seems to be more beneficial in HER2 positive breast cancer rather than HER2 negative breast cancer [8891]. Finn et al. [92] reported no benefit in patients with HER2 negative breast cancer randomized to receive paclitaxel with or without lapatinib.

Other drugs known to inhibit EGFR such as vandetanib, erlotinib, and afatinib, have only modest response rates in advanced breast cancer [93-97]. Most of the studies are limited by the low number of subjects; therefore, future studies are needed to corroborate these findings [93-98]. Despite the high expression of EGFR in TNBC, inhibition of this pathway had little effect in tumor progression, suggesting that alternate mechanisms are highly activated and are yet to be discovered. A new agent, panitumumab, is currently under investigation (NCT00894504, NCT01009983) $[99,100]$.

\section{Anti-Vascular Endothelial Growth Factor Receptor}

Vascular endothelial growth factor (VEGF) plays an important role in tumor angiogenesis. Agents that target VEGF may represent an attractive option for TNBC, which is known for its rapid clinical progression. Bevacizumab, a VEGF inhibitor, was approved to be used in addition to paclitaxel in Europe (E2100 trial) following a phase-III randomized trial that reported prolonged PFS in patients with advanced breast cancer [101]. Thereafter, several studies have introduced bevacizumab in their treatment regimens with encouraging results in PFS and an overall response rate in HER2-negative patients [102-104].

In a randomized study with 1,948 patients who received neoadjuvant epirubicin, cyclophosphamide, followed by docetaxel, or in conjunction with bevacizumab, the rate of pCR among TNBC patients was $39.3 \%$ for those who received bevacizumab and $27.9 \%$ in those who did not [105, 106]. However, in the phase-III BEATRICE trial $(n=2,591$ with TNBC), when bevacizumab was administered in the adjuvant setting in addition to chemotherapy and continued for one year, DFS and OS were not different between patients who received bevacizumab with chemotherapy versus those who received chemotherapy alone [107].

Other studies show benefits of the addition of bevacizumab to metastatic chemotherapy regimens, such as paclitaxel [101, 103, 108], docetaxel [102], and other compounds such as erlotinib [96]. In contrast, recent reports from the Breast Avastin Trial showed that TNBC patients treated with maintenance bevacizumab following treatment with docetaxel and capecitabine did not differ in their PFS and ORR when compared with hormonal receptor positive tumors [109]. The addition of bevacizumab to current metastatic therapies has been shown to increase the risk of drug toxicities without significant long-term benefit; thus the FDA has not granted the approval of this agent to treat advanced TNBC.

Sunitinib and sorafenib are anti-VEGFR tyrosine kinase inhibitors recently used in advanced HER2 negative metastatic breast cancer patients. Results provided by several clinical trials are inconclusive [110-114]. Clinical trials with 
sorafenib are currently investigating its effect on metastatic TNBC (NCT01194869) [115].

\section{CONCLUSION}

TNBC is a heterogeneous disease, and thus is challenging to treat. Definitive characterizations and appropriate treatments remain unresolved. Unfortunately, most of the clinical trials do not take into consideration the different subtypes of TNBC when reporting treatment outcomes. A study solely performed in TNBC based on the different subtypes is challenging since it may be hindered by low accrual. Understanding which treatments can benefit a particular patient cohort within the TNBC group requires further studies in correlating molecular phenotypes with specific targeted therapies.

\section{ABBREVIATIONS}

$$
\begin{aligned}
& \mathrm{ASCO}=\text { American Society of Clinical Oncology } \\
& \text { CAP }=\text { College of American Pathologist } \\
& \text { DFS = Disease-free survival } \\
& \text { EGFR = Epidermal growth factor receptor } \\
& \text { ER = Estrogen receptor } \\
& \text { FISH }=\text { Fluorescence in situ hybridization } \\
& \text { HER2 = Human epidermal factor receptor } 2 \\
& \text { IDC }=\text { Invasive ductal carcinoma } \\
& \text { IHC = Immunohistochemistry } \\
& \text { pCR = Pathologic complete response } \\
& \text { PFS = Progression-free survival } \\
& \text { PR = Progesterone receptor } \\
& \text { RFS = Recurrence-free survival } \\
& \text { TNBC }=\text { Triple negative breast cancer } \\
& \text { VEGF = Vascular endothelial growth factor }
\end{aligned}
$$

\section{CONFLICT OF INTEREST}

The authors confirm that there is no conflict of interest.

\section{ACKNOWLEDGEMENTS}

LP and AM are funded by the T32 DK007639; CC is funded by K08 CA125209.

\section{REFERENCES}

[1] American Cancer Society. Cancer facts \& figures 2013-2014. American Cancer Society; Atlanta, GA: 2013.

[2] O'Toole SA, Beith JM, Millar EK, et al. Therapeutic targets in triple negative breast cancer. J Clin Pathol 2013; 66: 530-42.

[3] Bayraktar S, Gluck S. Molecularly targeted therapies for metastatic triple-negative breast cancer. Breast Cancer Res Treat 2013; 138: 21-35.

[4] Perou CM, Sorlie T, Eisen MB, et al. Molecular portraits of human breast tumours. Nature 2000; 406: 747-52.

[5] Carey LA, Perou CM, Livasy CA, et al. Race, breast cancer subtypes, and survival in the carolina breast cancer study. JAMA 2006; 295: 2492-502.

[6] Hammond ME, Hayes DF, Dowsett M, et al. American society of clinical oncology/college of american pathologists guideline recommendations for immunohistochemical testing of estrogen and progesterone receptors in breast cancer. J Clin Oncol 2010; 28: 2784-95.
[7] Iwamoto T, Booser D, Valero V, et al. Estrogen receptor (ER) mRNA and ER-related gene expression in breast cancers that are $1 \%$ to $10 \%$ ER-positive by immunohistochemistry. J Clin Oncol 2012; 30: 729-34.

[8] Penault-Llorca F, Viale G. Pathological and molecular diagnosis of triple-negative breast cancer: a clinical perspective. Ann Oncol 2012; 23 (Suppl 6): vi19-22.

[9] Gown AM. Current issues in ER and HER2 testing by IHC in breast cancer. Mod Pathol 2008; 21 (Suppl 2): S8-15.

[10] Wolff AC, Hammond ME, Hicks DG, et al. Recommendations for human epidermal growth factor receptor 2 testing in breast cancer: American society of clinical oncology/college of american pathologists clinical practice guideline update. J Clin Oncol 2013; 31: 3997-4013

[11] Malorni L, Shetty PB, De Angelis C, et al. Clinical and biologic features of triple-negative breast cancers in a large cohort of patients with long-term follow-up. Breast Cancer Res Treat 2012; 136: 795-804.

[12] Metzger-Filho O, Sun Z, Viale G, et al. Patterns of recurrence and outcome according to breast cancer subtypes in lymph nodenegative disease: results from international breast cancer study group trials VIII and IX. J Clin Oncol 2013; 31: 3083-90.

[13] Sorlie T, Perou CM, Tibshirani R, et al. Gene expression patterns of breast carcinomas distinguish tumor subclasses with clinical implications. Proc Natl Acad Sci USA 2001; 98: 10869-74.

[14] Weigelt B, Mackay A, A'Hern R, et al. Breast cancer molecular profiling with single sample predictors: a retrospective analysis. Lancet Oncol 2010; 11: 339-49.

[15] Montagna E, Maisonneuve P, Rotmensz N, et al. Heterogeneity of triple-negative breast cancer: histologic subtyping to inform the outcome. Clin Breast Cancer 2013; 13: 31-9.

[16] Rakha EA, Elsheikh SE, Aleskandarany MA, et al. Triple-negative breast cancer: distinguishing between basal and nonbasal subtypes. Clin Cancer Res 2009; 15: 2302-10.

[17] Eiermann W, Bergh J, Cardoso F, et al. Triple negative breast cancer: proposals for a pragmatic definition and implications for patient management and trial design. Breast 2012; 21: 20-6.

[18] Thike AA, Cheok PY, Jara-Lazaro AR, et al. Triple-negative breast cancer: clinicopathological characteristics and relationship with basal-like breast cancer. Mod Pathol 2010; 23: 123-33.

[19] Nielsen TO, Hsu FD, Jensen K, et al. Immunohistochemical and clinical characterization of the basal-like subtype of invasive breast carcinoma. Clin Cancer Res 2004; 10: 5367-74.

[20] Fulford LG, Reis-Filho JS, Ryder K, et al. Basal-like grade III invasive ductal carcinoma of the breast: patterns of metastasis and long-term survival. Breast Cancer Res 2007; 9: R4.

[21] Thike AA, Iqbal J, Cheok PY, et al. Triple negative breast cancer: outcome correlation with immunohistochemical detection of basal markers. Am J Surg Pathol 2010; 34: 956-64.

[22] Thike AA, Iqbal J, Cheok PY, Tse GM, Tan PH. Ductal carcinoma in situ associated with triple negative invasive breast cancer: evidence for a precursor-product relationship. J Clin Pathol 2013; 66: 665-70.

[23] Prat A, Parker JS, Karginova O, et al. Phenotypic and molecular characterization of the claudin-low intrinsic subtype of breast cancer. Breast Cancer Res 2010; 12: R68.

[24] Lehmann BD, Bauer JA, Chen X, et al. Identification of human triple-negative breast cancer subtypes and preclinical models for selection of targeted therapies. J Clin Invest 2011; 121: 2750-67.

[25] Reis-Filho JS, Westbury C, Pierga JY. The impact of expression profiling on prognostic and predictive testing in breast cancer. J Clin Pathol 2006; 59: 225-31.

[26] Bauer KR, Brown M, Cress RD, Parise CA, Caggiano V. Descriptive analysis of estrogen receptor (ER)-negative, progesterone receptor (PR)-negative, and HER2-negative invasive breast cancer, the so-called triple-negative phenotype: a populationbased study from the California cancer Registry. Cancer 2007; 109: 1721-8.

[27] Fackenthal JD, Olopade OI. Breast cancer risk associated with BRCA1 and BRCA2 in diverse populations. Nat Rev Cancer 2007; 7: 937-48.

[28] Mavaddat N, Barrowdale D, Andrulis IL, et al. Pathology of breast and ovarian cancers among BRCA1 and BRCA2 mutation carriers: results from the consortium of investigators of modifiers of BRCA1/2 (CIMBA). Cancer Epidemiol Biomarkers Prev 2012; 21: $134-47$. 
[29] Lee E, McKean-Cowdin R, Ma H, et al. Characteristics of triplenegative breast cancer in patients with a BRCA1 mutation: results from a population-based study of young women. J Clin Oncol 2011; 29: 4373-80.

[30] Byrski T, Gronwald J, Huzarski T, et al. Pathologic complete response rates in young women with BRCA1-positive breast cancers after neoadjuvant chemotherapy. J Clin Oncol 2010; 28: 375-9.

[31] Fong PC, Boss DS, Yap TA, et al. Inhibition of poly(ADP-ribose) polymerase in tumors from BRCA mutation carriers. N Engl J Med 2009; 361: 123-34.

[32] Lips EH, Mulder L, Oonk A, et al. Triple-negative breast cancer: BRCAness and concordance of clinical features with BRCA1mutation carriers. Br J Cancer 2013; 108: 2172-7.

[33] Eerola H, Heikkila P, Tamminen A, et al. Histopathological features of breast tumours in BRCA1, BRCA2 and mutationnegative breast cancer families. Breast Cancer Res 2005; 7: R93100 .

[34] Anders CK, Winer EP, Ford JM, et al. Poly(ADP-Ribose) polymerase inhibition: "targeted" therapy for triple-negative breast cancer. Clin Cancer Res 2010; 16: 4702-10.

[35] Morris GJ, Naidu S, Topham AK, et al. Differences in breast carcinoma characteristics in newly diagnosed African-American and Caucasian patients: a single-institution compilation compared with the national cancer institute's surveillance, epidemiology, and end results database. Cancer 2007; 110: 876-84.

[36] Trivers KF, Lund MJ, Porter PL, et al. The epidemiology of triplenegative breast cancer, including race. Cancer Causes Control 2009; 20: 1071-82.

[37] Liedtke C, Mazouni C, Hess KR, et al. Response to neoadjuvant therapy and long-term survival in patients with triple-negative breast cancer. J Clin Oncol 2008; 26: 1275-81.

[38] Kelly CM, Bernard PS, Krishnamurthy S, et al. Agreement in risk prediction between the 21-gene recurrence score assay (Oncotype $\mathrm{DX}(\mathrm{R}))$ and the PAM50 breast cancer intrinsic classifier in earlystage estrogen receptor-positive breast cancer. Oncologist 2012; 17: 492-8

[39] Kim JE, Ahn HJ, Ahn JH, et al. Impact of triple-negative breast cancer phenotype on prognosis in patients with stage I breast cancer. J Breast Cancer 2012; 15: 197-202.

[40] Gamucci T, Vaccaro A, Ciancola F, et al. Recurrence risk in small, node-negative, early breast cancer: a multicenter retrospective analysis. J Cancer Res Clin Oncol 2013; 139: 853-60.

[41] Wang J, Shi M, Ling R, et al. Adjuvant chemotherapy and radiotherapy in triple-negative breast carcinoma: a prospective randomized controlled multi-center trial. Radiother Oncol 2011; 100: 200-4.

[42] Boyle P. Triple-negative breast cancer: epidemiological considerations and recommendations. Ann Oncol 2012; 23 (Suppl 6): vi 7-12.

[43] Hugh J, Hanson J, Cheang MC, et al. Breast cancer subtypes and response to docetaxel in node-positive breast cancer: use of an immunohistochemical definition in the BCIRG 001 trial. J Clin Oncol 2009; 27: 1168-76.

[44] Olszewski AJ, Migdady Y, Boolbol SK, et al. Effects of adjuvant chemotherapy in HER2-positive or triple-negative pT1ab breast cancers: a multi-institutional retrospective study. Breast Cancer Res Treat 2013; 138: 215-23.

[45] Martin M, Segui MA, Anton A, et al. Adjuvant docetaxel for highrisk, node-negative breast cancer. N Engl J Med 2010; 363: 220010 .

[46] Mackey JR, Martin M, Pienkowski T, et al. Adjuvant docetaxel, doxorubicin, and cyclophosphamide in node-positive breast cancer: 10-year follow-up of the phase 3 randomised BCIRG 001 trial. Lancet Oncol 2013; 14: 72-80.

[47] Martin M, Rodriguez-Lescure A, Ruiz A, et al. Molecular predictors of efficacy of adjuvant weekly paclitaxel in early breast cancer. Breast Cancer Res Treat 2010; 123: 149-57.

[48] Joensuu H, Kellokumpu-Lehtinen PL, Huovinen R, et al. Adjuvant capecitabine, docetaxel, cyclophosphamide, and epirubicin for early breast cancer: final analysis of the randomized FinXX trial. J Clin Oncol 2012; 30: 11-8.

[49] Colleoni M, Cole BF, Viale G, et al. Classical cyclophosphamide, methotrexate, and fluorouracil chemotherapy is more effective in triple-negative, node-negative breast cancer: results from two randomized trials of adjuvant chemoendocrine therapy for nodenegative breast cancer. J Clin Oncol 2010; 28: 2966-73

[50] Di Leo A, Desmedt C, Bartlett JM, et al. HER2 and TOP2A as predictive markers for anthracycline-containing chemotherapy regimens as adjuvant treatment of breast cancer: a meta-analysis of individual patient data. Lancet Oncol 2011; 12: 1134-42.

[51] Carey LA, Dees EC, Sawyer L, et al. The triple negative paradox: primary tumor chemosensitivity of breast cancer subtypes. Clin Cancer Res 2007; 13: 2329-34.

[52] Houssami N, Macaskill P, von Minckwitz G, Marinovich ML, Mamounas E. Meta-analysis of the association of breast cancer subtype and pathologic complete response to neoadjuvant chemotherapy. Eur J Cancer 2012; 48: 3342-54.

[53] von Minckwitz G, Untch M, Blohmer JU, et al. Definition and impact of pathologic complete response on prognosis after neoadjuvant chemotherapy in various intrinsic breast cancer subtypes. J Clin Oncol 2012; 30: 1796-804.

[54] Zelnak AB, Styblo TM, Rizzo M, et al. Final results from phase II trial of neoadjuvant docetaxel and capecitabine given sequentially or concurrently for HER2-negative breast cancers. Clin Breast Cancer 2013; 13: 173-9.

[55] Yardley DA, Peacock NW, Dickson NR, et al. A phase II trial of neoadjuvant gemcitabine, epirubicin, and docetaxel as primary treatment of patients with locally advanced or inflammatory breast cancer. Clin Breast Cancer 2010; 10: 217-23.

[56] Medioni J, Huchon C, Le Frere-Belda MA, et al. Neoadjuvant dose-dense gemcitabine plus docetaxel and vinorelbine plus epirubicin for operable breast cancer: improved prognosis in triplenegative tumors. Drugs R D 2011; 11: 147-57.

[57] Stemmler HJ, diGioia D, Freier W, et al. Randomised phase II trial of gemcitabine plus vinorelbine $v s$ gemcitabine plus cisplatin vs gemcitabine plus capecitabine in patients with pretreated metastatic breast cancer. Br J Cancer 2011; 104: 1071-8.

[58] Baselga J, Zambetti M, Llombart-Cussac A, et al. Phase II genomics study of ixabepilone as neoadjuvant treatment for breast cancer. J Clin Oncol 2009; 27: 526-34.

[59] Perez EA, Patel T, Moreno-Aspitia A. Efficacy of ixabepilone in ER/PR/HER2-negative (triple-negative) breast cancer. Breast Cancer Res Treat 2010; 121: 261-71.

[60] Yoshimoto M, Takao S, Hirata M, et al. Metronomic oral combination chemotherapy with capecitabine and cyclophosphamide: a phase II study in patients with HER2negative metastatic breast cancer. Cancer Chemother Pharmacol 2012; 70: 331-8

[61] Lemos Duarte I, da Silveira Nogueira Lima JP, Passos Lima CS, Deeke Sasse A. Dose-dense chemotherapy versus conventional chemotherapy for early breast cancer: A systematic review with meta-analysis. Breast 2012; 21: 343-49.

[62] Andre F, Zielinski CC. Optimal strategies for the treatment of metastatic triple-negative breast cancer with currently approved agents. Ann Oncol 2012; 23(Suppl 6): vi 46-51.

[63] Nitz UA, Mohrmann S, Fischer J, et al. Comparison of rapidly cycled tandem high-dose chemotherapy plus peripheral-blood stem-cell support versus dose-dense conventional chemotherapy for adjuvant treatment of high-risk breast cancer: results of a multicentre phase III trial. Lancet 2005; 366: 1935-44.

[64] Bryant HE, Schultz N, Thomas HD, et al. Specific killing of BRCA2-deficient tumours with inhibitors of poly(ADP-ribose) polymerase. Nature 2005; 434: 913-7.

[65] Tutt A, Robson M, Garber JE, et al. Oral poly(ADP-ribose) polymerase inhibitor olaparib in patients with BRCA1 or BRCA2 mutations and advanced breast cancer: a proof-of-concept trial. Lancet 2010; 376: 235-44.

[66] Sandhu SK, Schelman WR, Wilding G, et al. The poly(ADPribose) polymerase inhibitor niraparib (MK4827) in BRCA mutation carriers and patients with sporadic cancer: a phase 1 doseescalation trial. Lancet Oncol 2013; 14: 882-92.

[67] O'Shaughnessy J, Osborne C, Pippen JE, et al. Iniparib plus chemotherapy in metastatic triple-negative breast cancer. N Engl J Med 2011; 364: 205-14.

[68] O'Shaughnessy J, Schwartzberg LS, Danso MA, et al. A randomized Phase II study of iniparib (BSI-201) in combination with gemcitibine/carboplatin $(\mathrm{G} / \mathrm{C})$ in metastatic TNBC. J Clin Oncol 2011; 29: 15s:abstract 1007 . 
[69] Turner N, Moretti E, Siclari O, et al. Targeting triple negative breast cancer: is p53 the answer? Cancer Treat Reviews 2013; 39: $541-50$.

[70] Carey LA, Rugo HS, Marcom PK, et al. TBCRC 001: randomized phase II study of cetuximab in combination with carboplatin in stage IV triple-negative breast cancer. J Clin Oncol 2012; 30: 2615-

[71] Uhm JE, Park YH, Yi SY, et al. Treatment outcomes and clinicopathologic characteristics of triple-negative breast cancer patients who received platinum-containing chemotherapy. Int $\mathrm{J}$ Cancer 2009; 124: 1457-62.

[72] Ozkan M, Berk V, Kaplan MA, et al. Gemcitabine and cisplatin combination chemotherapy in triple negative metastatic breast cancer previously treated with a taxane/anthracycline chemotherapy: multicenter experience. Neoplasma 2012; 59: 3842.

[73] Gogas H, Pectasides D, Kostopoulos I, et al. Paclitaxel and carboplatin as neoadjuvant chemotherapy in patients with locally advanced breast cancer: A phase II trial of the Hellenic Cooperative Oncology Group. Clin Breast Cancer 2010; 10: 230-7.

[74] Frasci G, Comella P, Rinaldo M, et al. Preoperative weekly cisplatin-epirubicin-paclitaxel with G-CSF support in triplenegative large operable breast cancer. Ann Oncol 2009; 20: 118592.

[75] Frasci G, D'Aiuto G, Comella P, et al. Preoperative weekly cisplatin, epirubicin, and paclitaxel (PET) improves prognosis in locally advanced breast cancer patients: an update of the Southern Italy Cooperative Oncology Group (SICOG) randomised trial 9908. Ann Oncol 2010; 21: 707-16.

[76] Alba E, Chacon JI, Lluch A, et al. A randomized phase II trial of platinum salts in basal-like breast cancer patients in the neoadjuvant setting. Results from the GEICAM/2006-03, multicenter study. Breast Cancer Res Treat 2012; 136: 487-93.

[77] Byrski T, Dent R, Blecharz P, et al. Results of a phase II openlabel, non-randomized trial of cisplatin chemotherapy in patients with BRCA1-positive metastatic breast cancer. Breast Cancer Res 2012; 14: R110.

[78] Corkery B, Crown J, Clynes M, O'Donovan N. Epidermal growth factor receptor as a potential therapeutic target in triple-negative breast cancer. Ann Oncol 2009; 20: 862-7.

[79] Ryden L, Jirstrom K, Haglund M, Stal O, Ferno M. Epidermal growth factor receptor and vascular endothelial growth factor receptor 2 are specific biomarkers in triple-negative breast cancer. Results from a controlled randomized trial with long-term followup. Breast Cancer Res Treat 2010; 120: 491-8.

[80] Tang Y, Zhu L, Li Y, et al. Overexpression of epithelial growth factor receptor (EGFR) predicts better response to neo-adjuvant chemotherapy in patients with triple-negative breast cancer. J Transl Med 2012; 10(Suppl 1): S4.

[81] Rakha EA, El-Sayed ME, Green AR, et al. Prognostic markers in triple-negative breast cancer. Cancer 2007; 109: 25-32.

[82] Viale G, Rotmensz N, Maisonneuve $P$, et al. Invasive ductal carcinoma of the breast with the "triple-negative" phenotype: prognostic implications of EGFR immunoreactivity. Breast Cancer Res Treat 2009; 116: 317-28.

[83] Baselga J, Gomez P, Greil R, et al. Randomized phase II study of the anti-epidermal growth factor receptor monoclonal antibody cetuximab with cisplatin versus cisplatin alone in patients with metastatic triple-negative breast cancer. J Clin Oncol 2013; 31: 2586-92.

[84] O'Shaughnessy J, Weckstein DJ, Vukelja SJ, et al. Preliminary results of a randomized phase II study of weekly irinotecan/carboplatin with or without cetuximab in patients with metastatic breast cancer. San Antonio Breast Cancer Symposium; 2007 Breast Cancer Res Treat 106: Abstract 308.

[85] Kimple RJ, Horton JK, Livasy CA, et al. Phase I study and biomarker analysis of lapatinib and concurrent radiation for locally advanced breast cancer. Oncologist 2012; 17: 1496-503.

[86] Pestrin M, Bessi S, Puglisi F, et al. Final results of a multicenter phase II clinical trial evaluating the activity of single-agent lapatinib in patients with HER2-negative metastatic breast cancer and HER2-positive circulating tumor cells. A proof-of-concept study. Breast Cancer Res Treat 2012; 134: 283-9.

[87] Coombes RC, Tat T, Miller ML, et al. An open-label study of lapatinib in women with HER-2-negative early breast cancer: the lapatinib pre-surgical study (LPS study). Ann Oncol 2013; 24: 92430.

[88] Di Leo A, Gomez HL, Aziz Z, et al. Phase III, double-blind, randomized study comparing lapatinib plus paclitaxel with placebo plus paclitaxel as first-line treatment for metastatic breast cancer. J Clin Oncol 2008; 26: 5544-52.

[89] Boussen H, Cristofanilli M, Zaks T, et al. Phase II study to evaluate the efficacy and safety of neoadjuvant lapatinib plus paclitaxel in patients with inflammatory breast cancer. J Clin Oncol 2010; 28: 3248-55.

[90] Guan Z, Xu B, DeSilvio ML, et al. Randomized trial of lapatinib versus placebo added to paclitaxel in the treatment of human epidermal growth factor receptor 2-overexpressing metastatic breast cancer. J Clin Oncol 2013; 31: 1947-53.

[91] Rimawi MF, Mayer IA, Forero A, et al. Multicenter phase II study of neoadjuvant lapatinib and trastuzumab with hormonal therapy and without chemotherapy in patients with human epidermal growth factor receptor 2-overexpressing breast cancer: TBCRC 006. J Clin Oncol 2013; 31: 1726-31.

[92] Finn RS, Gagnon R, Di Leo A, et al. Prognostic and predictive value of HER2 extracellular domain in metastatic breast cancer treated with lapatinib and paclitaxel in a randomized phase III study. J Clin Oncol 2009; 27: 5552-8.

[93] Bernsdorf $\mathrm{M}$, Ingvar $\mathrm{C}$, Jorgensen $\mathrm{L}$, et al. Effect of adding gefitinib to neoadjuvant chemotherapy in estrogen receptor negative early breast cancer in a randomized phase II trial. Breast Cancer Res Treat 2011; 126: 463-70.

[94] Boer K, Lang I, Llombart-Cussac A, et al. Vandetanib with docetaxel as second-line treatment for advanced breast cancer: a double-blind, placebo-controlled, randomized Phase II study. Invest New Drugs 2012; 30: 681-7.

[95] Dickler MN, Cobleigh MA, Miller KD, Klein PM, Winer EP. Efficacy and safety of erlotinib in patients with locally advanced or metastatic breast cancer. Breast Cancer Res Treat 2009; 115: 11521.

[96] Montagna E, Cancello G, Bagnardi V, et al. Metronomic chemotherapy combined with bevacizumab and erlotinib in patients with metastatic HER2-negative breast cancer: clinical and biological activity. Clin Breast Cancer 2012; 12: 207-14.

[97] Schuler M, Awada A, Harter P, et al. A phase II trial to assess efficacy and safety of afatinib in extensively pretreated patients with HER2-negative metastatic breast cancer. Breast Cancer Res Treat 2012; 134: 1149-59.

[98] Gutteridge E, Agrawal A, Nicholson R, et al. The effects of gefitinib in tamoxifen-resistant and hormone-insensitive breast cancer: a phase II study. Int J Cancer 2010; 126: 1806-16.

[99] Clinicaltrials.gov. Available at: http://clinicaltrials.gov/ct2/show/ NCT00894504?term=nct00894504\&rank=1

[100] Clinicaltrials.gov. Web site available at: http://clinicaltrials.gov/ct2/ show/NCT01009983?term $=$ nct01009983\&rank=1

[101] Miller K, Wang M, Gralow J, et al. Paclitaxel plus bevacizumab versus paclitaxel alone for metastatic breast cancer. N Engl J Med 2007; 357: 2666-76.

[102] Miles DW, Chan A, Dirix LY, et al. Phase III study of bevacizumab plus docetaxel compared with placebo plus docetaxel for the first-line treatment of human epidermal growth factor receptor 2-negative metastatic breast cancer. J Clin Oncol 2010; 28 : 3239-47.

[103] Robert NJ, Dieras V, Glaspy J, et al. RIBBON-1: randomized, double-blind, placebo-controlled, phase III trial of chemotherapy with or without bevacizumab for first-line treatment of human epidermal growth factor receptor 2-negative, locally recurrent or metastatic breast cancer. J Clin Oncol 2011; 29: 1252-60.

[104] Lang I, Inbar MJ, Kahan Z, et al. Safety results from a phase III study (TURANDOT trial by CECOG) of first-line bevacizumab in combination with capecitabine or paclitaxel for HER-2-negative locally recurrent or metastatic breast cancer. Eur J Cancer 2012; 48: 3140-9.

[105] von Minckwitz G, Eidtmann H, Rezai M, et al. Neoadjuvant chemotherapy and bevacizumab for HER2-negative breast cancer. N Engl J Med 2012; 366: 299-309.

[106] Gerber B, Loibl S, Eidtmann H, et al. Neoadjuvant bevacizumab and anthracycline-taxane-based chemotherapy in 678 triplenegative primary breast cancers; results from the geparquinto study (GBG 44). Ann Oncol 2013; 24: 2978-84. 
[107] Cameron D, Brown J, Dent R, et al. Adjuvant bevacizumabcontaining therapy in triple-negative breast cancer (BEATRICE): primary results of a randomised, phase 3 trial. Lancet Oncol 2013; 14: 933-42.

[108] Gray R, Bhattacharya S, Bowden C, Miller K, Comis RL. Independent review of E2100: a phase III trial of bevacizumab plus paclitaxel versus paclitaxel in women with metastatic breast cancer. J Clin Oncol 2009; 27: 4966-72.

[109] Bisagni G, Musolino A, Panebianco M, et al. The breast avastin trial: phase II study of bevacizumab maintenance therapy after induction chemotherapy with docetaxel and capecitabine for the first-line treatment of patients with locally recurrent or metastatic breast cancer. Cancer Chemother Pharmacol 2013; 71: 1051-7.

[110] Yardley DA, Dees EC, Myers SD, et al. Phase II open-label study of sunitinib in patients with advanced breast cancer. Breast Cancer Res Treat 2012; 136: 759-67.

[111] Burstein HJ, Elias AD, Rugo HS, et al. Phase II study of sunitinib malate, an oral multitargeted tyrosine kinase inhibitor, in patients with metastatic breast cancer previously treated with an anthracycline and a taxane. J Clin Oncol 2008; 26: 1810-6.

[112] Bergh J, Bondarenko IM, Lichinitser MR, et al. First-line treatment of advanced breast cancer with sunitinib in combination with docetaxel versus docetaxel alone: results of a prospective, randomized phase III study. J Clin Oncol 2012; 30: 921-9.

[113] Gradishar WJ, Kaklamani V, Sahoo TP, et al. A double-blind, randomised, placebo-controlled, phase $2 \mathrm{~b}$ study evaluating sorafenib in combination with paclitaxel as a first-line therapy in patients with HER2-negative advanced breast cancer. Eur J Cancer 2013; 49: 312-22.

[114] Baselga J, Segalla JG, Roche H, et al. Sorafenib in combination with capecitabine: an oral regimen for patients with HER2-negative locally advanced or metastatic breast cancer. J Clin Oncol 2012; 30: $1484-91$.

[115] Clinicaltrials.gov. Web site. Available at: http://clinicaltrials.gov/ct2/show/NCT01194869?term=nct01194869\&rank=1

(C) Porro et al.; Licensee Bentham Open.

This is an open access article licensed under the terms of the Creative Commons Attribution Non-Commercial License (http://creativecommons.org/licenses/by-nc/ 3.0/) which permits unrestricted, non-commercial use, distribution and reproduction in any medium, provided the work is properly cited. 